Journal of Management and Bussines (JOMB)

Volume 2, Nomor 2, Desember 2020

p-ISSN : 2656-8918

e-ISSN: $2684-8317$

DOI : https://doi.org/10.31539/jomb.v2i2.695

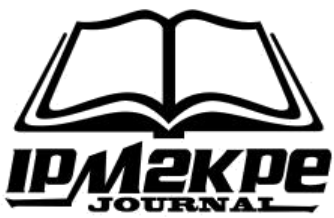

\title{
PERAN JOB INSECURITY DAN JOB SATISFACTION TERHADAP
} KOMITMEN ORGANISASI

\author{
Siti Nurleni ${ }^{1}$, Erry Sunarya ${ }^{2}$, Faizal Mulia Z. $^{3}$ \\ Universitas Muhammadiyah Sukabumi ${ }^{1,2,3}$ \\ Snurleni81@gmail.com ${ }^{1}$
}

\begin{abstract}
ABSTRAK
Tujuan dari penelitian ini adalah untuk mengukur peran job insecurity dan job satisfaction terhadap komitmen organisasi karyawan pada PT. Doosan Jaya 3 Kabupaten Sukabumi. Metode yang digunakan dalam penelitian ini adalah metode deskriptif dan asosiatif. Pengambilan sampel dalam penelitian ini menggunakan simple random sampling yang termasuk dalam propotional sampling dengan menyebarkan 100 kuesioner kepada karyawan bagian produksi PT. Doosan Jaya 3 di Kabupaten Sukabumi. Hasil penelitian ini menunjukkan bahwa uji simultan job insecurity dan job satisfaction memperoleh signifikansi sebesar $0,000(<0,05)$ dan nilai $F_{\text {hitung }}$ sebesar $251,457\left(>\mathrm{F}_{\text {tabel }}=2,36\right)$. Simpulan, job insecurity dan job satisfaction berpengaruh positif dan signifikan terhadap komitmen organisasi.
\end{abstract}

Kata Kunci: Job Insecurity, Job Satisfaction, Komitmen Organisasi

\section{ABSTRACT}

The purpose of this study was to measure the role of job insecurity and job satisfaction with the organizational commitment of employees at PT. Doosan Jaya 3 Sukabumi Regency. The method used in this research is descriptive and associative methods. Sampling in this study using simple random sampling which is included in the proportional sampling by distributing 100 questionnaires to employees of the production division of PT. Doosan Jaya 3 in Sukabumi Regency. The results of this study indicate that the simultaneous test of job insecurity and job satisfaction obtained a significance of $0.000(<0.05)$ and the Fcount value of 251.457 (> Ftable $=2.36)$. In conclusion, job insecurity and job satisfaction have a positive and significant effect on organizational commitment.

Keywords: Job Insecurity, Job Satisfaction, Organizational Commitment

\section{PENDAHULUAN}

Menghadapi persaingan yang semakin ketat, setiap pelaku ekonomi dituntut untuk bisa memiliki strategi dalam mengembangkan dan mempertahankan usaha yang sudah dijalankan. Dalam menjalankan usaha tidak hanya strategi saja yang digunakan tetapi perusahaan juga membutuhkan Sumber Daya Manusia (SDM) yang baik. Seorang karyawan yang memiliki kemampuan yang baik dan berkualitas cenderung memiliki kinerja yang baik pula bagi perusahaan. Untuk membangun pencapaian dan tujuan yang 
telah ditetapkan, maka perusahaan harus memenuhi keinginan yang diharapkan oleh karyawan. Keberhasilan seseorang dalam suatu bidang pekerjaan ditentukan oleh tingkat kompetensi yang dimiliki, kepuasan kerja yang dirasakan karyawan dan juga komitmennya terhadap bidang yang dikerjakannya. Para karyawan yang memiliki komitmen di bidang pekerjaannya akan mempunyai rasa ikut atau keterlibatan dalam berorganisasi dan selalu berusaha untuk tetap menjadi bagian dari organisasi tersebut.

Komitmen organisasi menjadi sangat penting karena akan berdampak pada penurunan kinerja para karyawan bahkan loyalitas karyawan. Para karyawan yang berkomitmen akan lebih bertanggung jawab terhadap pekerjaan yang sudah diberikan kepadanya dibandingkan dengan karyawan dengan komitmen rendah atau bahkan yang tidak mempunyai komitmen. Komitmen organisasi yang rendah dapat memicu terjadinya turnover intention. Komitmen organisasi ialah derajat dimana para karyawan mempercayai dan menerima tujuan-tujuan organisasi serta tidak akan meninggalkan perusahaan.

Seorang karyawan yang memiliki komitmen tinggi akan mempunyai ketertarikan atau keterlibatan dalam pekerjaannya dan tetap ingin menjadi bagian dari organisasi atau mempunyai rasa loyalitas terhadap perusahaan. Komitmen yang kuat dapat membawa dampak positif, diantaranya yaitu peningkatan prestasi kerja, motivasi kerja, masa kerja dan karyawan lebih rajin masuk kerja sehingga mengurangi absensi dan menurunkan turnover.

Job insecurity (ketidakamanan kerja) diartikan sebagai perasaan tertekan yang dirasakan oleh para karyawan mengenai ketidaksesuaian harapan-harapan karyawan terhadap keberlangsungan pekerjaannya. Ketidaknyamanan kerja yang dirasakan oleh para karyawan akan mempengaruhi sikap kerja karyawan tersebut. Jika para karyawan telah merasa tidak aman dalam pekerjaannya, maka akan berdampak pada penurunan komitmen karyawan itu sendiri, bahkan rasa keinginan untuk keluar dari perusahaan itu itu juga semakin tinggi. Smithson \& Lewis (2000) mengartikan bahwa job insecurity adalah kondisi psikologis seseorang (karyawan) yang menunjukan perasaan bingung atau perasaaan tidak aman yang disebabkan oleh lingkungan yang berubah-ubah (perceived impermance). Kondisi ini muncul karena banyaknya jenis pekerjaan yang sifatnya sesaat atau pekerjaan kontrak. Apabila banyak karyawan yang mengalami job insecuruty, maka akan berdampak pada kepuasan kerja yang dirasakan oleh karyawan. 
Semakin tingginya job insecurity, maka kepuasan kerja para karyawan juga akan menjadi rendah. Jika kepuasan yang dirasakan oleh karyawan semakin rendah, maka komitmen organisasi karyawan juga ikut menurun.

Job Satisfaction (kepuasan kerja) merupakan salah satu elemen yang cukup penting dalam organisasi. Hal ini disebabkan karena kepuasan kerja akan mempengaruhi perilaku kerja. Menurut Hapsari (2009) terdapat perbedaan kepuasan kerja antara pegawai tetap dan pegawai kontrak. Kepuasan pegawai tetap lebih tinggi dibanding kepuasan kerja karyawan kontrak. Status karyawan yang berbeda juga akan menghasilkan hak dan kewajiban yang berbeda pula sehingga berdampak pada penurunan kepuasan kerja pada karyawan.

Berdasarkan uraian di atas, peneliti tertarik untuk mengkaji tentang job insecurity dan job satisfaction pada karyawan PT. Doosan Jaya 3 Kabupaten Sukabumi. Penelitian ini bertujuan untuk mengukur peran job insecurity dan job satisfaction terhadap komitmen organisasi pada PT. Doosan Jaya 3 Kabupaten Sukabumi.

\section{KAJIAN TEORI}

\section{Job Insecurity}

Teori tentang job insecurity disampaikan pertama kali oleh Greenhalgh \& Rosenblatt (1984). Mereka mendefinisikan job insecurity sebagai ketidakberdayaan yang dirasakan oleh seorang karyawan untuk mempertahankan situasi kerjanya di tengah situasi kerja yang terancam. Adapun menurut Helgren \& Sverke (2002) job insecurity adalah pandangan subjektif seseorang mengenai situasi atau peristiwa yang mengancam pekerjaan di tempatnya bekerja.

Ketidakamanan kerja (job insecurity) merupakan kondisi dimana seorang karyawan mempunyai perasaan tertekan yang samakin meningkat karena ketidakstabilan terhadap status kepegawaian mereka. Perasaaan tidak aman tersebut akan membawa kepada sikap kerja karyawan yang berdampak pada penurunan komitmen karyawan yang akan semakin rendah, bahkan rasa keinginan untuk keluar dari perusahan pun akan semakin meningkat. Hal ini juga sesuai dengan pendapat Smithson \& Lewis (2002) yang mengatakan bahwa job insecurity adalah kondisi psikologis seorang (karyawan) dimana karyawan menunjukan rasa bingung atau merasa tidak aman dikarenakan kondisi lingkungan yang berubah-ubah (perceived 
impermanance). Karyawan dengan job insecurity yang tinggi dalam pekerjaannya akan menyebabkan terjadinya perubahan sikap kerja karyawan. Dalam hal ini rasa tidak aman yang dirasakan para karyawan akan mengakibatkan penurunan kepuasan kerja yang dirasakan oleh karyawan.

Ada 3 aspek rasa aman dalam bekerja yang saling berkaitan yakni: 1) job security, rasa aman dalam bekerja yaitu kesempatan untuk menjadi pegawai tetap pada perusahaan yang sama; 2) employer security, menjadi karyawan dengan jenis pekerjaan atau pada lokasi yang berbeda namun masih dalam perusahaan yang sama; 3) employment security, mencakup didalamnya kesempatan untuk berganti perusahaan.

\section{Job Satisfaction}

Job satisfaction (kepuasan kerja) salah satu sarana penting pada sumber daya manusia. Dalam sebuah organisasi kepuasan kerja merupakan perasaan dimana seseorang bisa merasakan harapan sesuai dengan keinginannya dan apa yang mereka telah lakukan sesuai dengan hasil yang diterima karyawan tersebut. Kepuasan kerja akan terlaksana dengan baik jika seorang karyawan merasa cukup dan puas dengan apa yang mereka terima. Hal ini sejalan dengan pendapat Wibowo (2008) yang mengatakan bahwa kepuasan kerja merupakan sikap positif atau negatif yang dilakukan individual terhadap pekerjaan mereka. Dengan kata lain bahwa kepuasan kerja merupakan salah satu elemen yang cukup penting dalam organisasi. Hal ini disebabkan karena kepuasan kerja juga dapat mempengaruhi perilaku kerja seperti malas, rajin, produktif dan beberapa jenis perilaku lainnya yang sangat penting dalam sebuah organisasi.

\section{Komitmen Organisasi}

Menurut McShane \& Von Glinow (2008) menyatakan bahwa komitmen organisasi memberikan pengaruh yang sangat kuat, dimana seseorang dapat mengindentifikasikan permintaan dan sangat termotivasi untuk melaksanakannya bahkan ketika sumber motivasi tidak hadir lagi.

Robbins \& Judge (2015) mengelompokan komitmen organisasi dengan tiga indikator terpisah, yaitu: 1) komitmen efektif (effective commitmen), terjadi apabila karyawan ingin menjadi bagian dari organisasi kerena adanya ikatan emosional (emotional attachment) atau merasa mempunyai nilai sama dengan organisasi; 2) 
komitmen berkelanjutan (continuance commitmen), yaitu kemauan individu untuk tetap bertahan dalam organisasi karena tidak menemukan pekerjaan lain; 3) komitmen normatif (normative commitmen), timbul dari nilai-nilai para karyawannya. Karyawan bertahan menjadi anggota organisasi karena adanya kesadaran bahwa berkomitmen terhadap organisasi merupakan hal yang memang seharusnya dilakukan.

\section{METODE PENELITIAN}

Penelitian ini dilaksanakan di PT. Doosan Jaya 3 Kabupaten Sukabumi. Metode penelitian yang digunakan adalah metode deskriptif dan asosiatif. Pengambilan sampel dalam penelitian ini menggunakan teknik proportional sampling dengan menggunakan non random sampling. Ciri utama sampling ini adalah tidak semua anggota sampel diberi kesempatan untuk dipilih sebagai anggota sampel. Pengambilan sampel dilakukan dengan menyebarkan 100 kuisioner kepada karyawan bagian produksi PT. Doosan Jaya 3 Kabupaten Sukabumi. Teknik analisa data yang digunakan adalah uji validitas, uji reabilitas, analisis regresi liner berganda, termasuk uji koefesien determinasi, koefisien korelasi ganda dan pengujian hipotesis menggunakan uji secara stimultan (uji F).

\section{HASIL PENELITIAN}

\section{Uji Validitas}

Suatu penelitian yang menggunakan kuisioner sebagian besar pengukurannya perlu di uji validitasnya. Syarat minimum untuk memenuhi validitas adalah 0,3

Tabel 1.

Hasil Uji Validitas

\begin{tabular}{ccccc}
\hline Variabel & Item & $\mathrm{r}^{-}$Hitung & $\mathrm{r}^{-}$Kritis & Keterangan \\
\hline \multirow{3}{*}{ Job Insecurity $(\mathrm{X} 1)$} & 1 & 0,694 & 0,3 & Valid \\
\cline { 2 - 5 } & 2 & 0,732 & 0,3 & Valid \\
\cline { 2 - 5 } & 3 & 0,666 & 0,3 & Valid \\
\cline { 2 - 5 } & 4 & 0,715 & 0,3 & Valid \\
\cline { 2 - 5 } Job Satisfaction $(\mathrm{X} 2)$ & 1 & 0,516 & 0,3 & Valid \\
\cline { 2 - 5 } & 2 & 0,565 & 0,3 & Valid \\
\cline { 2 - 5 } & 3 & 0,676 & 0,3 & Valid \\
\cline { 2 - 5 } & 5 & 0,674 & 0,3 & Valid \\
\hline \multirow{3}{*}{ Komitmen Organisasi (Y) } & 1 & 0,722 & 0,3 & Valid \\
\cline { 2 - 5 } & 2 & 0,691 & 0,3 & Valid \\
\cline { 2 - 5 } & 3 & 0,768 & 0,3 & Valid \\
\hline
\end{tabular}

(Sumber: Data Primer (Kuisioner), 2019) 
Berdasarkan tabel 1, dapat diketahui bahwa nilai kolerasi antara skor item variabel job insecurity, job satisfaction dan komitmen organisasi memiliki skor diatas 0,3 , sehinga seluruh butir instrumen item dinyatakan valid.

\section{Uji Realibilitas}

Hasil uji realibilitas dengan menggunakan rumus Cronbach's Alpha dengan bantuan SPSS 24 dapat dilihat pada tabel berikut ini:

Tabel 2.

Hasil Uji Realibilitas

\begin{tabular}{cccc}
\hline \multirow{2}{*}{ Variabel } & \multicolumn{2}{c}{ Koefisien Cronbach's Alpha } & \multirow{2}{*}{ Keterangan } \\
\cline { 2 - 3 } & Hitung & Standar & \\
\hline Job Insecurity & 0,654 & 0,6 & Reliabel \\
Job Satisfaction & 0,736 & 0,6 & Reliabel \\
Komitmen Organisasi & 0.600 & 0,6 & Reliabel \\
\hline
\end{tabular}

(Sumber: Data Primer (Kuisioner), 2019)

Berdasarkan tabel 2, hasil menunjukkan bahwa nila $\alpha$ hitung $>\alpha$ standar $(0,6)$, sehingga dapat disimpulkan bahwa variabel-variabel yang dipakai dalam penelitian ini adalah reliabel. Hal tersebut bermakna bahwa varibael-variabel tersebut dapat digunakan untuk penelitian selanjutnya karena dapat diandalkan.

\section{Koefesien Korelasi Ganda}

Tabel 3.

Hasil Koefisien Korelasi Ganda

\begin{tabular}{ccccc}
\hline \multicolumn{5}{c}{ Model Summary } \\
\hline Model & $\mathrm{R}$ & $\mathrm{R}$ Square & Adjusted R Square & Std. Error of the Estimate \\
\hline 1 & $.916^{\mathrm{a}}$ & .838 & .835 & .587 \\
\hline a. Predictors: (Constant), Job Satisfaction, Job Insecurity \\
\hline (Sumber: Data Primer (Kuisioner), 2019)
\end{tabular}

Tabel 3 menunjukkan bahwa nilai $\mathrm{R}$ yang diperoleh adalah sebesar 0,916. Hal tersebut bermakna bahwa terdapat hubungan yang cukup kuat antara job insecurity, job satisfaction terhadap komitmen organisasi karyawan. 


\section{Koefisien Determinasi $\left(\mathbf{R}^{2}\right)$}

Tabel 4.

Hasil Koefisien Determinasi

\begin{tabular}{ccccc}
\hline \multicolumn{5}{c}{ Model Summary } \\
\hline Model & $\mathrm{R}$ & $\mathrm{R}$ Square & Adjusted $\mathrm{R}$ Square & Std. Error of the Estimate \\
\hline 1 & $.916^{\mathrm{a}}$ & .838 & .835 & .587 \\
\hline
\end{tabular}

a. Predictors: (Constant), Job Satisfaction, Job Insecurity

(Sumber: Data Primer (Kuisioner), 2019)

Berdasarkan hasil tabel 4, dapat diketahui bahwa adjusted $\mathrm{R}^{2}$ adalah sebesar 0,838. Hal ini menunjukkan bahwa 83,8\% variasi komitmen organisasi karyawan dapat dijelaskan oleh job insecurity dan job satisfaction. Sedangkan sisanya 16,2\% dipengaruhi oleh faktor yang tidak diteliti dalam penelitian ini.

\section{Hasil Analisis Regresi Linier Berganda}

Tabel 5.

Hasil Analisis Regresi Linier Berganda

\begin{tabular}{|c|c|c|c|c|c|c|}
\hline \multicolumn{7}{|c|}{ Coefficients $^{a}$} \\
\hline \multirow{2}{*}{\multicolumn{2}{|c|}{ Model }} & \multicolumn{2}{|c|}{$\begin{array}{c}\text { Unstandardized } \\
\text { Coefficients }\end{array}$} & \multirow{2}{*}{$\begin{array}{c}\text { Standardized } \\
\text { Coefficients }\end{array}$} & \multirow[t]{2}{*}{$\mathrm{t}$} & \multirow[t]{2}{*}{ Sig. } \\
\hline & & $\mathrm{B}$ & Std. Error & & & \\
\hline 1 & (Constant) & -1.597 & .641 & & -2.493 & .014 \\
\hline & Job Insecurity & -.089 & .054 & -.104 & -1.653 & .102 \\
\hline & Job Satisfaction & .751 & .048 & .993 & 15.740 & .000 \\
\hline
\end{tabular}

a. Dependent Variable: Komitmen Organisasi

(Sumber: Data Primer (Kuisioner), 2019)

Berdasarkan output regresi linier berganda pada tabel 5, maka dapat diperoleh persamaan sebagai berikut:

$Y=(-1597)+(-089) X_{1}+751 X_{2}$

\section{Uji Signifikan Secara Simultan (Uji F)}

Tabel 6. Hasil Uji F

\begin{tabular}{llccccc}
\hline \multicolumn{7}{c}{ ANOVA $^{\mathrm{a}}$} \\
\hline Model & \multicolumn{7}{c}{ Sum of Squares } & df & Mean Square & F & Sig. \\
\hline \multirow{2}{*}{1} & 173.119 & 2 & 86.560 & 251.457 & $.000^{\mathrm{b}}$ \\
\cline { 2 - 7 } & Regression & 33.391 & 97 & .344 & & \\
\cline { 2 - 7 } & Residual & Total & 206.510 & 99 & & \\
\end{tabular}

a. Dependent Variable: Komitmen Organisasi

b. Predictors: (Constant), Job Satisfaction, Job Insecurity

(Sumber: Data Primer (Kuisioner), 2019) 
Berdasarkan tabel 6, hasil uji yang dilakukan menunjukkan bahwa nilai $F_{\text {hitung }}$ adalah sebesar 251,457 $\left(>\mathrm{f}_{\text {tabel }}=2,36\right)$ dengan signifikansi sebesar 0,000 $(<0,05)$, artinya job insecurity dan job satisfaction berpengaruh positif dan signifikan terhadap komitmen organisasi karyawan.

\section{PEMBAHASAN}

Kemajuan di bidang teknologi dan perdagangan mendorong SDM untuk terus berusaha secara optimal dalam meningkatan kualitasnya. Peningkatan kualitas tersebut dibuktikan dengan adanya komitmen dalam organisasi (Kristine, 2017). Komitmen organisasi merupakan bentuk loyalitas karyawan terhadap perusahaan. Komitmen organisasi dipandang sebagai keadaan dimana seorang karyawan sejalan dan mendukung penuh pada tujuan organisasi (Novita et al., 2016). Komitmen yang tinggi membuat karyawan menjadi lebih setia dan bekerja keras untuk mencapai tujuan serta kemajuan perusahaan. Komitmen ini akan memberikan kepuasan pada karyawan dalam bekerja dan didukung secara timbal balik oleh perusahaan (Taurisa \& Ratnawati, 2012). Menurut Haris, (2017) komitmen organisasi karyawan mampu meningkatkan kualitas kinerja karyawan pada organisasi.

Organisasi harus memberi perhatian penuh dan membuat karyawan percaya terhadap organisasi. Hal tersebut dapat menciptakan komitmen karyawan terhadap organisasi. Jika komitmen karyawan telah diperoleh, maka organisasi akan mendapatkan karyawan yang setia dan mampu bekerja sebaik mungkin untuk kepentingan organisasi. Keadaan ini sangat baik bagi organisasi untuk mencapai tujuannya, karena organisasi mendapat dukungan penuh dari anggotanya sehingga bisa berkonsentrasi secara penuh pada tujuan yang diprioritaskan (Kurniawan, 2011).

Saeed et al., (2014) mengemukakan bahwa pada dasarnya organisasi tidak dapat menghilangkan turnover intention, namun hal tersebut dapat mengurangi peluang terjadinya turnover intention itu sendiri. Karyawan akan mengalami rasa tidak aman (job insecurity) yang meningkat karena ketidakstabilan status kepegawaian dan tingkat pendapatan yang tidak bisa diramalkan, sehingga berakibat pada intensi pindah kerja (turnover intention) yang cenderung meningkat (Hanafiah, 2014).

Berdasarkan hasil penelitian, job insecurity berpengaruh positif dan signifikan terhadap komitmen organisasi karyawan PT. Doosan Jaya 3 Kabupaten Sukabumi. Hal 
ini berbeda dengan hasil temuan Dewi \& Suana (2016) dan Yunanti \& Prabowo (2014) yang menyatakan bahwa terdapat hubungan negatif antara antara job insecurity dan komitmen organisasi, artinya semakin tinggi job insecurity, maka akan semakin rendah komitmen organisasi. Begitupun sebaliknya, semakin rendah job insecurity akan semakin tinggi komitmen organisasi.

Hasil penelitian ini juga menunjukkan bahwa job satisfaction berpengaruh positif dan signifikan terhadap komitmen organisasi karyawan PT. Doosan Jaya 3 Kabupaten Sukabumi. Hal ini sejalan dengan hasil penelitian Dewi \& Suana (2016) bahwa kepuasan kerja berpengaruh positif dan signifikan terhadap komitmen organisasi. Menurutnya dibandingkan dengan job insecurity, kepuasan kerja dan keadilan organisasi justru memberikan pengaruh paling besar terhadap komitmen organisasi karyawan.

\section{SIMPULAN}

Tiap-tiap indikator dari variabel job insecurity, job satisfaction dan komitmen organisasi dalam penelitian ini dapat mewakili dari masing-masing variabelnya dan sekaligus dapat dihandalkan sebagai indikator yang dapat digunakan oleh peneliti di masa mendatang.

Berdasarkan uji F, variabel job insecurity dan job satisfaction berpengaruh positif dan signifikan terhadap komitmen organisasi karyawan PT. Doosan Jaya 3 Kabupaten Sukabumi.

\section{DAFTAR PUSTAKA}

Dewi, N. L. S., \& Suana, I. W. (2016). Ketidakamanan Pekerjaan Pengaruh, Kepuasan Kerja dan Keadilan Organisasi terhadap Komitmen Organisasi Karyawan Kontrak. E-Jurnal Manajemen Unud, 5(5), 3000-3026

Greenhalgh, L., \& Rosenblatt, Z. (1984). Job Insecurity: Toward Conseptual Clarity. The Academy of Management Review, 9(3), 438-448

Hanafiah, M. (2014). Pengaruhkepuasan Kerja dan Ketidakamanan Kerja (Job Insecurity) dengan Intensi Pindah Kerja (Turnover Intention) pada Karyawan PT. Buma Desa Suara Kecamatan Sambaliung Kabupaten Berau. E-Journal Psikologi, 1(3), 303-312

Hapsari, A. D (2009). Perbedaan Tingkat Kepuasan Kerja pada Karyawan Tetap dan Karyawan Kontrak. Skripsi. Universitas Sanata Dharma

Haris, H. (2017). Pengaruh Kepuasan Kerja dan Komitmen Organisasi terhadap Kualitas Layanan di PT . Asuransi Jasindo (Persero) Kantor Cabang Korporasi dan Ritel Bandung. Jurnal Ekonomi Manajemen Sumber Daya, 19(2), 135-151 
Helglgren, J., \& Sverke, M. (2002). A Two-Dimensional Approach to Job Insecurity: Consequencess for Employee Attuades and Wll-Being. European Journal of Work and Organizational Psychology, 8(2): 179-195

Kristine, E. (2017). Pengaruh Kepuasan Kerja dan Komitmen Organisasi terhadap Kinerja Melalui Motivasi Kerja Pegawai Alih Daya (Outsourcing) di PT. Mitra Karya Jaya Sentosa. Jurnal Eksekutif, 14(2), 384-401

Kurniawan, N. R. M. (2011). Pengaruh Komitmen Organisasi, Budaya Organisasi, dan Kepuasan Kerja terhadap Kinerja Organisasi Publik (Studi pada Pemerintah Daerah Kabupaten Demak). Skripsi. Universitas Diponogoro

Mcshane, S. L., \& Glinow, M. A. V. (2008). Organizational Behavior, Fourth Edition. United States Of America: Mcgraw-Hill International

Novita, N., Sunuharjo, B. S., \& Ruhana, I. (2016). Pengaruh Kepuasan Kerja dan Komitmen Organisasional terhaddap Kinerja Karyawan (Studi pada PT. Telekomunikasi Indonesia, Tbk Witel Jatim Selatan, Malang). Jurnal Administrasi Bisnis, 34(1), 38-46

Robbins, S. P., \& Judge, T. A. (2015). Perilaku Organisasi, Edisi 16, Diterjemahkan: Ratna Saraswati dan Febriella Sirait. Jakarta: Salemba Empat

Saeed, I., Momina, W., Sidra, S., \& Muhammad, R. (2014). The Relationship of Turnover Intention with Job Satisfaction, Job Performance, Leader Member Exchange, Emotional Intelligence and Organizational Commitment. International Journal of Learning and Development, 4(2), 242-256

Smithson, J., \& Lewis, S. (2000). Is Job Insecurty Changing the Physhology Contract?. Personal Review, 29(6), 1-5

Taurisa, C. M., \& Ratnawati, I. (2012). Analisis Pengaruh Budaya Organisasi dan Kepuasan Kerja terhadap Komitmen Organisasional dalam Meningkatkan Kinerja Karyawan (Studi pada PT. Sido Muncul Kaligawe Semarang). Jurnal Bisnis dan Ekonomi (JBE), 19(2), 170-187

Wibowo, W. (2008). Manajemen Kinerja. Jakarta: Rajagrafindo Persada

Yunanti, Y. D., \& Prabowo, S. (2014). Komitmen Organisasi Ditinjau dari Job Insecurity pada Karyawan Outsourcing. Psikodimensia, 13(1), 37-46 